\title{
ANALISIS SEVEN TOOLS PADA PENGENDALIAN KUALITAS PROSES VULKANISIR BAN 1000 RING 20 DI CV CITRA BUANA MANDIRI SURABAYA
}

\author{
Andrianto Eko Saputra ${ }^{1}$, Nina Aini Mahbubah ${ }^{2}$ \\ Program Studi Teknik Industri, Fakultas Teknik, Universitas Muhammadiyah Gresik \\ Jl. Sumatera 101 GKB Gresik 61121, Indonesia \\ andre.eko32@gmail.com¹,n.mahbubah@umg.ac.id ${ }^{2}$
}

Submitted January 8, 2021; Revised January 29, 2021; Accepted January 30, 2021

\begin{abstract}
Abstrak
CV.Citra Buana Mandiri merupakan salah satu perusahaan jasa yang bergerak pada bidang vulkanisir ban bekas yang diolah menjadi ban baru. Dalam proses produksinya perusahaan masih memiliki tantangan berupa defect pada produk yang disebabkan oleh faktor eksternal dan internal perusahaan sehingga produk yang dihasilkan tidak sesuai dengan standart mutu yang ditetapkan oleh perusahaan. Tujuan dari penelitian ini adalah mengidentifikasi penyebab defect ban ring 20 , menganalisis apakah defect produk masih dalam batas kendali dan memberikan usulan perbaikan guna meningkatkan kualitas ban ring 20. Penelitian ini menggunakan metode seven tools dengan hasil penelitian sebagai berikut, faktor yang menyebabkan defect ban 1000 ring 20 adalah faktor manusia, mesin, bahan baku, lingkungan dan metode yang selanjutnya didapatkan 13 kemungkinan akar penyebab permasalahan. Proporsi defect dalam produk ban 1000 ring 20, dapat disimpulkan bahwa produk tersebut masih dalam batas kendali namun berdasarkan standart toleransi perusahaan persentase defect yang ada masih berada di luar standart yang telah di tetapkan yaitu sebanyak 1 persen dan 13 langkah usulan perbaikan.
\end{abstract}

Kata Kunci : ban, vulkanisir, cacat, kualitas, seven tools

\begin{abstract}
CV. Citra Buana Mandiri is a service enterprise which provide service such as retreading of used tires. During retread production process, there were found defects which caused by external and internal factors so the final product are not in accordance with the quality standards set by the firm. The purpose of this research is to identify the causes of ring 20 tire defects, analyze whether the product defects are still within control limits and provide recommendations for improvements to improve the quality of ring 20 tires. Tseven tools was used as research approach with final result as follows: identifying factors that cause 1000 tire defects. ring 20 is the factor of human, machine, raw material, environment and method, then we get 13 possible root causes of the problem. The proportion of defects in the 1000 ring 20 tire product, it can be concluded that the product is still within control limits, but based on the company's standard tolerance, the percentage of defects that are still outside the predetermined standard is 1 percent and 13 improvement along production stages in order to maintaining excellent quality.
\end{abstract}

Key Words : tire, retread, quality, defect, seven tools

\section{PENDAHULUAN}

Organisasi bisnis dengan tujuan menghasilkan profit diklasifikasikan menjadi 2, yaitu usaha jasa dan bisnis manufaktur. Jasa merupakan hasil dari aktivitas menghasilkan output berupa service tanpa adanya perubahan fisik [1].
Sedangkan manufaktur adalah proses industri yang merubah dari bahan mentah menjadi bahan jadi. CV.Citra Buana Mandiri merupakan salah satu perusahaan jasa yang bergerak pada bidang vulkanisir ban bekas yang diolah menjadi ban baru. 
Sejarah berdirinya CV. Citra Buana Mandiri adalah distributor resmi ban Good Years. Tahun 1996 karena banyaknya permintaan dari konsumen untuk ban vulkanisir sehingga perusahaan membangun pabrik vulkanisir ban untuk memenuhi permintaan pasar.

Perusahaan dalam bidang apapun dituntut untuk selalu meningkatkan kualitas produk. Kebijakan perusahaan dan permintaan konsumen pada produk berkualitas semakin meningkat. Pelaku bisnis melakukan upaya perbaikan mutu produk secara berkesinambungan guna menjadi pemenang di pasar dan mampu mengimbangi kompetitor [2]. Perbaikan terus menerus pada proses produksi merupakan salah satu pendekatan penjaminan mutu perusahaan manufaktur atau perusahaan jasa [3].

Proses vulkanisir ban dilakukan dalam dua belas tahap. Inisial Inspeksi Adalah tahap awal yaitupemeriksaan fisik ban dan penentuan kelayakan ban bekas utuk dilakukan vulkanisir. Tahapan ke dua adalah buffing atau pemarutan bertujuan untuk menghilangkan tapak yang sudah aus dan menjadikan ban simetris dan rata. Tahap ke tiga yaitu skiving adalah pemarutan kembali casing yang telah melalui proses buffing dan dilanjutkan cementing adalah proses pemberian cairan cement ke seluruh permukaan ban.

Setelah proses cementing selesai, tahapan selanjutnya adalah Repairing, merupakan proses penambalan permukaan dalam ban yang lubang tembus dengan cushion gum dan juga karet radial. Filling merupakan tahap ke enam yaitu memperbaiki semua cacat pada casing, lubang pada casing dibersihkan kemudian ditembel dengan repair rope, dilanjutkan proses building adalah proses penempelan tread rubber pada casing dan proses enveloping yaitu pembungkusan ban yang hendak divulkanisir dengan bungkus khusus.
Tahap ke sembilan adalah rimming, dilakukan pemasangan ban dalam ke dalam ban yang hendak divulkanisir yang kemudian ditutup dengan pelek. Air Evacuation merupakan proses ke sepuluh dilakukan dengan cara ban di press vacuum dua arah yaitu dari dalam dengan bantuan ban dalam dengan di pompa angin dan dari luar dengan menggunakan envelope. Tahap ke sebelas adalah curing merupakan proses pemanasan dengan temperatur $110 \quad{ }^{\circ} \mathrm{C}$ didalam chamber selama 240 menit dan tahap akhir adalah painting, mengecat seluruh permukaan ban dengan minyak BP serta melakukan pengecekan akhir untuk memastikan bahwa ban yang telah selesai memenuhi firm's quality standard sebelum diserahkan kembali ke konsumen.

Pada duabelas tahapan proses vulkanisir ban, terdapat output dihasilkan tidak sesuai dengan standart mutu yang ditetapkan oleh perusahaan. Jenis ban 1000 ring 20 merupakan tipe produk dengan temuan ketidaksesuaian terbanyak. Tabel 1. merupakan data defect yang terjadi selama bulan Agustus 2018 - Januari 2019.

Tabel 1. Defect periode Agustus 2018Januari 2019

\begin{tabular}{lllll}
\hline \multirow{2}{*}{ Bulan } & \multirow{2}{*}{$\begin{array}{l}\text { Jumlah } \\
\text { Produksi }\end{array}$} & \multicolumn{2}{c}{ Jenis Defect } & Total \\
\cline { 3 - 5 } & & Kembung & $\begin{array}{l}\text { tidak } \\
\text { matang }\end{array}$ \\
\hline Agu-18 & 680 & 11 & 14 & 25 \\
Sep-18 & 669 & 15 & 11 & 26 \\
Okt-18 & 695 & 11 & 12 & 23 \\
Nov-18 & 596 & 13 & 10 & 23 \\
Des-18 & 650 & 8 & 12 & 20 \\
Jan-19 & 728 & 16 & 13 & 29 \\
\hline
\end{tabular}

Dari Tabel 1 dapat dilihat jenis defect kembung dan tidak matang sebesar tiga persen per bulan. Pengecekan kualitas yang dilakukan perusahaan selama ini belum terstandarisasi dengan benar. Karena pengecekan kualitas hanya dilakukan pada produk jadi, namun pada 
kenyataannya produk defect juga ditemukan di work in process. Referensi [4] menyatakan bahwa seharusnya proses perbaikan kualitas dilakukan mulai dari awal sampai akhir lini produksi dan garansi kualitas pada konsumen akhir. Karakteristik langsung suatu produk dapat dinilai dari kualitas produk atau jasa yang dihasilkan [5].

Berdasarkan identifikasi permasalahan kualitas tersebut, maka diperlukan teknik pengendalian kualitas untuk menganalisis permasalahan yang terjadi, sehingga dapat di temukan sebuah solusi yang tepat untuk meminimalisir defect yang ada pada proses produksi. Seven quality tools adalah sebuah metode yang bisa digunakan untuk menganalisa produk defect tersebut guna mengendalikan kualitas produk. Kategori defect ada dua yaitu defect kembung dan tidak matang dapat dilihat pada Gambar 1.

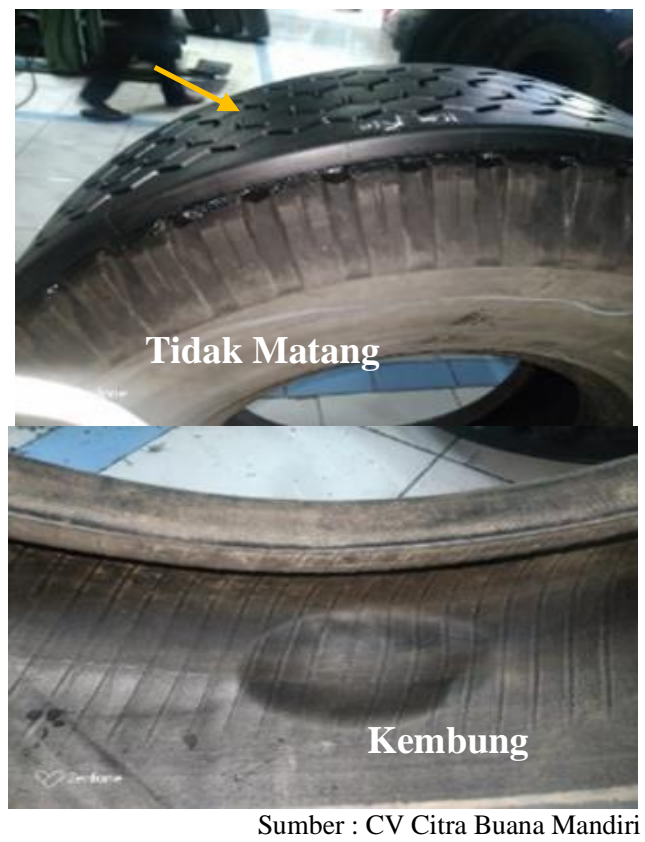

\section{Gambar 1. Visualisasi Jenis defect}

Tujuan dari penelitian ini adalah untuk mengidentifikasi penyebab - penyebab defect ban ring 20, menganalisis apakah defect produk masih dalam batas pengendalian dan memberikan usulan - usulan perbaikan guna meningkatkan kualitas ban ring 20 .

Pengendalian penjaminan mutu merupakan suatu pendekatan yang digunakan untuk menjamin sebuah proses produksi barang dan jasa pada semua tahapan lini produksi. Referensi [6] mengidentifikasi definisi Kualitas menurut Montgomery adalah:

"Aktivitas rekayasa pengelolaan dimulai dengan tahapaj pendefinisian karakteristik kualitas produk, melakukan monitoring perbandingan dengan base line spesifikasi kualitas produk dan diakhiri dengan perbaikan proses jika terjadi penyimpangan anytara hasil proses di lini produksi dan standar yang ditetapkan perusahaan."

Produk sesuai karakteristik dan standar dan dan biaya produksi minimal merupakan sasaran utama hasil pengendalian mjutu di semua lini produksi [7]. Seven tools analysis merupakan pendekatan penjaminan mutu dengan deskripsi tahapan pengendalian kualitas sebagai berikut [8] :

Diagram Proses atau Flowchart proses pengumpulan data, mengimplementasikan data juga merupakan ringkasan visual dari data itu sehingga memudahkan dalam memahami alur proses perbaikan [7].

Check Sheet atau lembar pemeriksaan merupakan lembar pengumpulan data yang digunakan untuk memudahkan dan menyederhanakan pencatatan data [9].

Histogram adalah diagram batang yang digunakan untuk menunjukan adanya depresi data dan distribusi frekuensi [10].

Pareto Diagram digunakan untuk mengelola kesalahan, masalah atau reject agar dapat memusatkan titik kesalahan untuk melakukan perbaikan [11]. Hasil Pareto yaitu identifikasi menyeluruh jenis penyimpangan yang terjadi dan merupakan masalah utama dari nilai terbesar hingga penyimpangan dengan nilai paling kecil [12].

Scatter Diagram atau dalam istilah lain dinamakan dengan diagram pancar menunjukan hubungan dari suatu penyebab 
terhadap akibat atau kedekatan dari dua data [13].

Control Chart digunakan untuk menentukan batas-batas produk apakah masih dalam kondisi terkontrol apa diluar kendali dengan cara menghitung menggunakan control attribute [11]

Diagram Sebab Akibat menggambarkan penyebab terjadinya defect pada input proses produksi, yaitu tenaga kerja, bahan baku, modal, lingkungan kerja, metode kerja dan peralatan kerja[6]. Proses penyusunan diagram dimulai dari temuan didapatkan langsung dari lapangan dan selanjutnya dilakukan klarifikasi menggunakan metode brainstorming dengan team pengendalian kualitas perusahaan [14].

\section{METODE PENELITIAN}

Descriptive analysis merupakan pendekatan penelitian yang digunakan, yaitu mendeskripsikan akibat dari fenomena defect pada proses vulkanisir ban. Pendalaman fenomena terjadinya defect menggunakan pendekatan seven tolos dan di implementasikan pada obyek penelitian yaitu análisis kualitas produk ban ring 20. Tahapan penelitian dimulai dengan metode walk through survey pada proses vulkanisir ban. Pada tahap ini dilakukan penelusuran di lapangan dengan melihat setiap proses pembuatan vulkanisir ban dari material datang sampai pembuatan vulkanisir jadi. Pada tahap selanjutnya dilakukan identifikasi dari sebuah masalah yang membuat proses produksi vulkanisir ban 1000 ring 20 tidak optimal.

Studi pustaka dilakukan dengan menyesuaikan permasalahan yang teridentifikasi dengan referensi pengendalian mutu yang membahas tentang seven quality tools dengan permasalahan yang sama pada industri yang berbeda.

Tahap pengumpulan data dilakukan secara langsung dari data perusahaan dan juga data melalui observasi langsung. Data yang di kumpulkan adalah data total produksi enam bulan terakhir sejak agustus 2018 januari 2019 dan juga data jumlah produk ban yang defect.

Data yang telah dikumpulkan di olah dan dianalisis dengan menggunakan metode seven quality tools yaitu diagram proses, check sheet, histogram, pareto diagram, scatter diagram, control chart dan diagram sebab akibat. Tahap terakhir adalah kesimpulan tentang temuan hasil penelitian setelah dilakukan analisis dan saran memberikan saran bagi perusahan dan juga penelitian selanjutnya.

\section{HASIL DAN PEMBAHASAN}

Pada Bagian ini analisis data dilakukan untuk mengidentifikasi masalah dan mengetahui akar penyebab permasalahan sehingga didapatkan sebuah usulan perbaikan guna meminimalisir defect yang terjadi pada produk ban 1000 ring 20 .

\section{Diagram Proses / Flowchart}

Aliran proses produksi vulkanisir ban dari bahan baku sampai produk jadi terbagi dalam beberapa proses, adapun proses secara keseluruhan dapat dilihat pada Gambar 2.

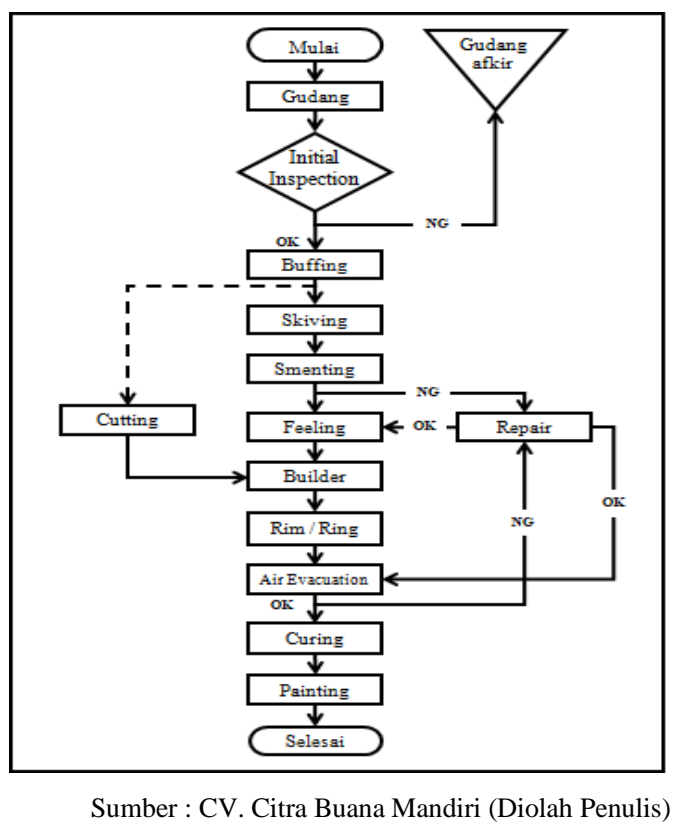

Gambar 2. Diagram Proses Produksi Ban 


\section{Check Sheet}

Dalam proses produksi ban 1000 ring $20 \mathrm{di}$ CV. Citra Buana Mandiri telah menerapkan check sheet produk cacat. Kemudian check sheet tersebut di rekap dalam satu bulan. Data rekap check sheet produk cacat dapat dilihat pada Tabel 2.

Tabel 1. Rekapitulasi Data Check Sheet

\begin{tabular}{|c|c|c|c|}
\hline Bulan & Jenis Cacat & Tally & Jumlah \\
\hline \multirow{3}{*}{ Agu-2018 } & kembung & IIIII IIIII I & \\
\hline & tidak matang & IIIII IIIII & 25 \\
\hline & & IIII & \\
\hline \multirow{2}{*}{ Sep-2018 } & kembung & IIIII & 26 \\
\hline & tidak matang & IIIII IIIII I & \\
\hline \multirow{3}{*}{ Окт-2018 } & kembung & IIIII IIIII I & \\
\hline & & & 23 \\
\hline & Tidak matang & IIIII IIIII II & \\
\hline \multirow{3}{*}{ Nov-2018 } & kembung & IIIII IIIIII III & \\
\hline & & & 23 \\
\hline & tidak matang & IIIII IIIII & \\
\hline \multirow{3}{*}{ DES-2018 } & kembung & IIIII III & \\
\hline & & & 20 \\
\hline & tidak matang & IIIII IIIII II & \\
\hline \multirow[t]{2}{*}{ JAN-2019 } & kembung & $\begin{array}{ll}\text { IIIII } & \text { IIIII } \\
\text { IIIII I } & \end{array}$ & 29 \\
\hline & Tidak matang & IIIII IIIII III & \\
\hline
\end{tabular}

\section{Histogram}

Data produk defect kemudian diolah dalam histogram untuk mengetahui karakteristik dari data defect yang terjadi. Diagram histogram dapat dilihat pada Gambar 3.

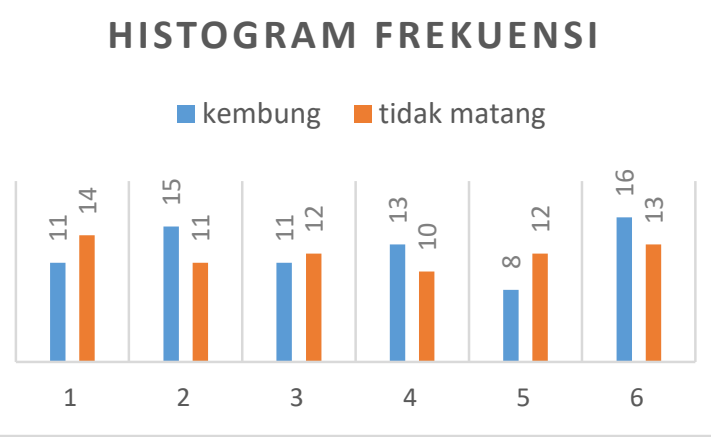

\section{Gambar 3. Histogram Perbandingan Defect}

Dari diagram 3. dapat diketahui bahwa frekuensi defect produksi ban 1000 ring 20 di CV Citra Buana Mandiri pada 6 bulan terakhir cenderung fluktuatif, terlihat titik tertinggi dari defect produksi ban 1000 ring 20 yakni pada bulan Januari yaitu sebesar 29 kejadian. Dengan defect paling tinggi pada jenis defect kembung sebanyak 16 frekuensi defect.

\section{Pareto Diagram}

Pada diagram pareto menggambarkan urutan jenis defect dari nilai terbesar hingga nilai terkecil digambarkan pada Diagram 4.

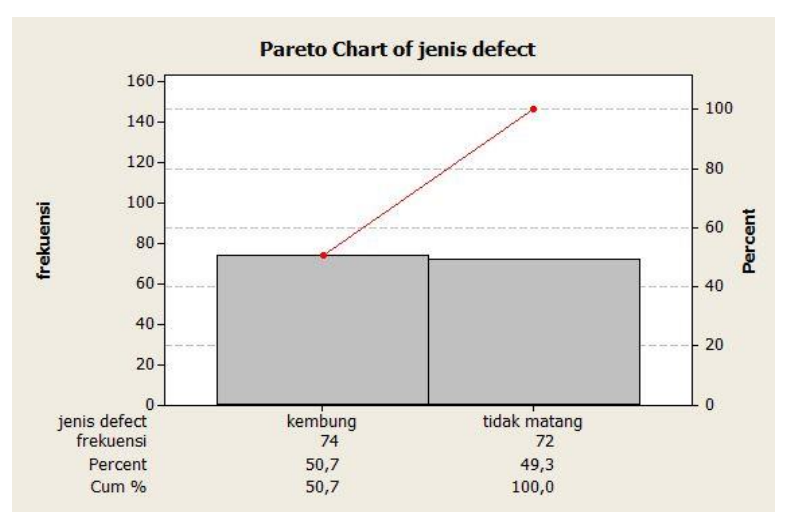

\section{Gambar 4. Pareto Diagram}

Berdasarkan diagram pareto pada Gambar 4. dapat dilihat bahwa menurut prioritas jenis defect yang terjadi memiliki frekuensi yang hampir sama dengan presentase 50,7 $\%$ untuk cacat kembung dan 49,3\% untuk cacat tidak matang.

\section{Scatter Diagram}

Untuk mengetahui apakah ada korelasi antara banyaknya produksi ban 1000 ring 20 (X) dengan jumlah defect (Y) digambarkan dalam diagram Scatter. Dengan menggunakan aplikasi M.S Excel data kemudian di olah. Olahan data tersebut berupa diagram scatter dengan menghubungkan gambaran dot pada Gambar 5. 


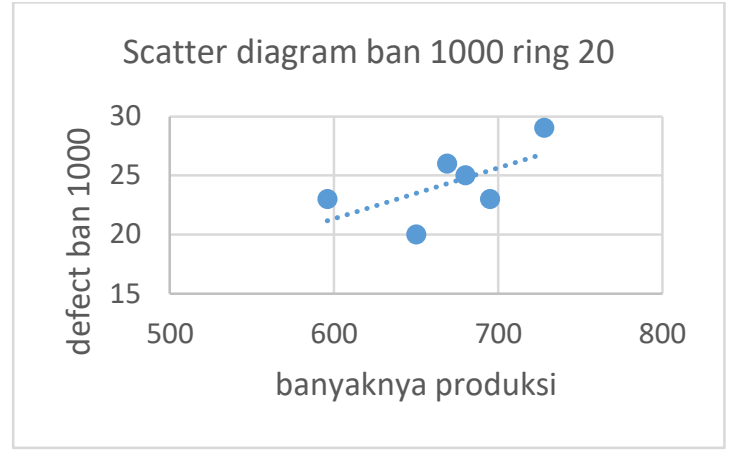

\section{Gambar 5. Scatter Diagram}

Berdasarkan diagram scatter, dapat di simpulkan bahwa antara variabel $\mathrm{X}$ adalah banyaknya produksi ban 1000 ring 20 dan variabel $\mathrm{Y}$ adalah kuantitas defect tidak mempunyai korelasi, yang artinya banyaknya jumlah produksi ban 1000 ring 20 tidak berdampak pada tingginya defect. Hal ini dapat kita lihat dari sebaran titik Diagram scatter yang tidak bergerak naik ataupun turun melainkan menyebar secara acak. Sebaran acak diagram scatter ini dapat menjadi data acuan, bahwa banyaknya jumlah produk ban 1000 ring 20 tidak memperngaruhi banyaknya produk defect.

\section{Control Chart}

Karena sampel yang diambil 100\% dari inspeksi yaitu total produksi ban 1000 ring 20 tiap hari maka digunakan peta kendali p (p-chart). Karena apabila ukuran sampel atau ukuran sub kelompok yang digunakan pada setiap kali pengamatan lebih banyak atau meningkat, maka batas - batas pengendali menjadi lebih rendah. Namun apabila banyaknya sampel atau sub kelompok yang digunakan pada setiap kali pengamatan turun dan berkurang, maka batas - batas pengendali akan menjadi lebih banyak atau meningkat. Data primer dimasukkan kedalam program excel untuk melihat p-bar ( nilai tengah ), LCL / BKB ( batas kendali bawah ), dan juga UCL / BKA (batas kendali) hasil p-chart dapat dilihat pada Gambar 6. Berikut dijabarkan perhitungan batas $\mathrm{k}$ endali pada control chart p-chart.

$$
p^{-}=\Sigma p n / \Sigma n
$$

$\mathrm{p}^{-}$: Proporsi Kesalahan

$\Sigma \mathrm{p}$ : Total Kerusakan Produk

$\Sigma \mathrm{n}$ : Total Pengambilan Sampel

$$
\overline{\mathrm{p}}=0,2150 / 6=0,0358
$$

$\mathrm{CL}=0,0358$

$$
\begin{array}{lc}
\mathrm{UCL} \quad=0,0358+ & 3 \sqrt{0,0358}(1- \\
0,0358 / 670)=0,0574 & \\
\mathrm{LCL}=\quad 0,0358- & 3 \sqrt{\overline{0,0358}}(1- \\
0,0358 / 670)=0,0143 &
\end{array}
$$

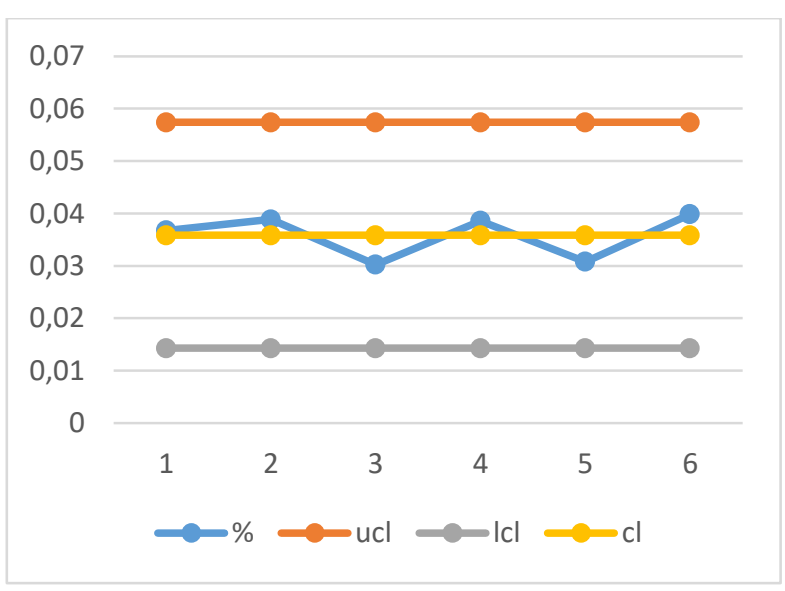

Gambar 6. P-Chart Ban 1000 Ring 20

Setelah control chart dibuat, dapat di analisis banyakya proposi defect dalam produk ban 1000 ring 20. Dari data di atas dapat kita simpulkan bahwa produk tersebut masih dalam batas kendali namun berdasarkan standart toleransi perusahaan persentase defect yang berada di luar standar yang telah di tentukan yaitu sebanyak 1 persen.

\section{Diagram Sebab Akibat}

Diagram sebab akibat menunjukkan hubungan antara masalah yang ada dengan kemungkinan penyebab beserta faktor yang mempengaruhinya. Faktor penyebab secara umum adalah manusia, mesin, metode kerja, lingkungan dan material. Dari hasil identifikasi berdasarkan faktor penyebab didapatkan akar penyebab dari setiap faktor penyebab terjadinya defect ban 1000 ring 20. Berikut merupan hasi 
identifikasi kemungkinan akar penyebab permasalahan yang disajikan dalam bentuk diagram sebab akibat yang dapat dilihat pada Gambar 7.

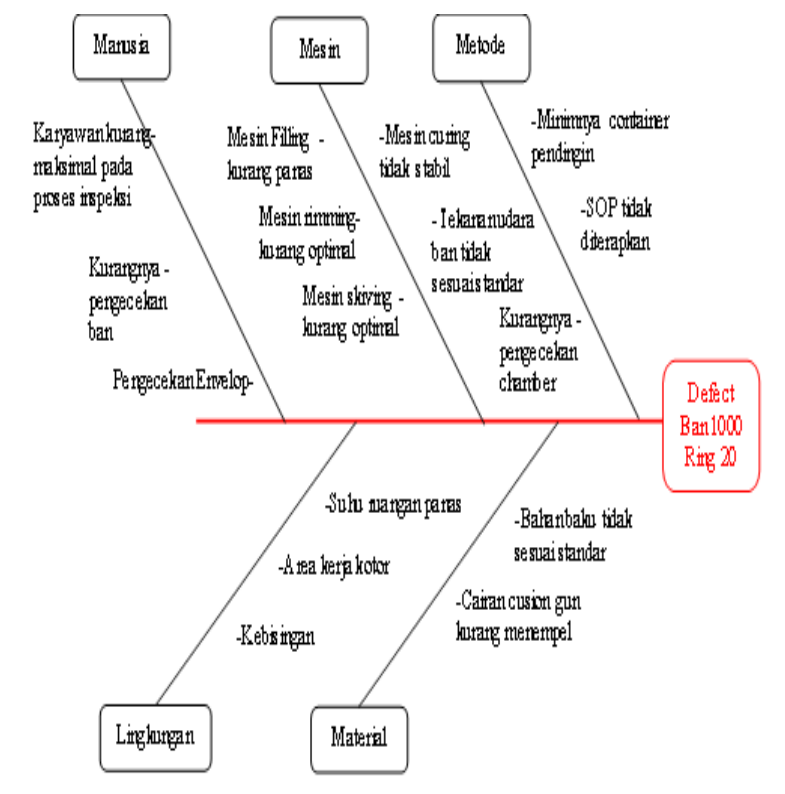

Gambar 7. Diagram Sebab Akibat Defect Ban 1000 Ring 20

Akar penyebab terjadinya defect produk ban ring 20 digambarkan pada Diagram 8 . Identifikasi penyebab permasalahan didapatkan dari walk through survey dan brainstorming dengan bagian pengendalian mutu. Lima penyebab defect yaitu tenaga kerja, mesin alat bantu produksi, métode kerja, bahan baku, dan lingkungan kerja.

Hasil temuan di lapangan dan brainstorming dengan team pengendalian mutu dikonfigurasikan pada diagram Tulang Ikan Gambar 8. dapat Terjadinya defect kembung dan ban tidak rata disebabkan oleh karyawan yaitu Karyawan kurang maksimal pada proses inspeksi. Pada proses produksi pada bagian insial inspeksion operatornya sering kelolosan dan menyebkan terhambatnya waktu produksi. Kurangnya pengecekan ban yaitu pada saat memasukan ban ke dalam proses produksi karyawan kurang teliti memilih ban yang layak atau tidak layak untuk di masukkan pada saat proses vulkanisir.

Terjadinya penyimpangan mutu dari mesin diketahui Mesin rimming kurang optimal, pada proses rimming sering kali mengalami kendala pada saat pemasangan pelek ban. Mesin curing tidak stabil terjadi pada proses pemanasan ban suhu yang kurang stabil bisa menyebabkan vulkanisir ban mengalami banyak kecacatan seperti kembung dan tidak matang. Mesin filling kurang panas disebabkan pada saat penambalan ban mesin filling suhu pada mesin tersebut kurang optimal untuk digunakan. Mesin skiving kurang optimal mempengaruhi proses pelubangan ban hasil proses buffing tidak sesuai standart yang ditetapkan Tekanan udara ban tidak sesuai standar dikarenakan kurang stabilnya mesin envelople.

Metode kerja diidentifikasi sebagai penyebab kecacatan ke tiga yaitu dijumpai bahwa Standart Operational Procedure (SOP) tidak diterapkan pada proses produksinya pekerja mengabaikan sop mereka hanya menggunakan perkiraan mereka sehingga tiap bagian yang pada proses produksi tidak terstandarisasi. Minimnya container pendingin disebabkan kapasitas pendingin yang kurang dengan hasil produksi yang di capai perusahaan. Kurangnya pengecekan chamber yaitu pada proses ini suhu curing kurang diperhatikan sehingga sering terjadi kecacatan pada proses tersebut.

Akar penyebab bahan baku yaitu terdapat bahan baku tidak sesuai standar dan bahan baku yang diterima kurang baik dan tetap di produksi sehingga bahan baku tersebut memiliki kualitas yang kurang baik dan rentang cacat. Cairan cusion gum kurang menempel di ban sehingga ban tersebut tidak bisa menempel dengan tread. Penyebab terakhir yaitu lingkungan fisik kerja ditemukan adanya suhu ruangan yang panas, terjadi kebisingan akibat proses kerja dan kebersihan area kerja tidak terjaga. 


\section{Rekomendasi}

Setelah diketahui akar penyebab defect yang terjadi, kemudian dilakukan brainstorming untuk mengetahui usulan perbaikan yang tepat. Tabel 3. merupakan rekapitulasi rekomendasi dengan mengacu pada permasalahan dan dampak yang ditimbulkan.

\section{Tabel 3. Rekomendasi}

\begin{tabular}{|c|c|c|}
\hline Problem & Dampak & Rekomendasi \\
\hline $\begin{array}{l}\text { Mesin } \\
\text { curing } \\
\text { tidak } \\
\text { stabil }\end{array}$ & $\begin{array}{lr}\text { Ban } & \text { mengalami } \\
\text { kecacatan } & \text { seperti } \\
\text { kembung } & \text { dan tidak } \\
\text { matang } & \end{array}$ & $\begin{array}{ll}\text { Perawatan } & \text { mesin } \\
\text { curing secara } & \text { teratur } \\
\text { tiap bulanya } & \end{array}$ \\
\hline $\begin{array}{l}\text { Mesin } \\
\text { skiving } \\
\text { kurang } \\
\text { optimal }\end{array}$ & $\begin{array}{l}\text { Pelobangan ban } \\
\text { setelah proses buffing } \\
\text { tidak standart yang } \\
\text { ditentukan }\end{array}$ & $\begin{array}{l}\text { Sebaiknya dilakukan } \\
\text { perawatan mesin } \\
\text { skiving secara teratur }\end{array}$ \\
\hline $\begin{array}{l}\text { Mesin } \\
\text { rimming } \\
\text { kurang } \\
\text { optimal }\end{array}$ & $\begin{array}{l}\text { Pada saat pemasangan } \\
\text { pelek mesin tersebut } \\
\text { tidak maksimal bisa } \\
\text { menyebabkan ban } \\
\text { tidak matang }\end{array}$ & $\begin{array}{l}\text { Perawatan mesin } \\
\text { rimming } \\
\text { dilakukan } \\
\text { berkala sehingga bisa } \\
\text { mengurangi cacat } \\
\text { pada proses produksi } \\
\text { tersebut }\end{array}$ \\
\hline $\begin{array}{l}\text { Mesin } \\
\text { filling } \\
\text { kurang } \\
\text { panas }\end{array}$ & $\begin{array}{l}\text { Penambalan ban jika } \\
\text { suhu mesin filling } \\
\text { tidak panas maka } \\
\text { pemasangan tread } \\
\text { tidak bisa menyatu } \\
\text { dengan ban }\end{array}$ & $\begin{array}{l}\text { Pemeliharaan mesin } \\
\text { secara preventif dan } \\
\text { mengeceknya tiap } \\
\text { minggunya }\end{array}$ \\
\hline $\begin{array}{l}\text { Tekanan } \\
\text { udara ban } \\
\text { kurang } \\
\text { maksimal }\end{array}$ & $\begin{array}{lr}\begin{array}{l}\text { Pada saat } \\
\text { pemanasan }\end{array} & \begin{array}{r}\text { proses } \\
\text { tekanan } \\
\text { udara }\end{array} \\
\text { maksimal } & \text { bisa } \\
\text { mnyebabkan } & \\
\text { kecacatan } & \text { kembung } \\
\text { pada ban tersebut } \\
\text { pada proses curing }\end{array}$ & $\begin{array}{l}\text { Dilakukan } \\
\text { pengecekan mesin } \\
\text { tiap harinya sehingga } \\
\text { bisa mengurangi } \\
\text { kecacatan pada proses } \\
\text { produksi }\end{array}$ \\
\hline $\begin{array}{l}\text { Karyawan } \\
\text { kurang } \\
\text { maksimal } \\
\text { pada } \\
\text { proses } \\
\text { inspeksi }\end{array}$ & $\begin{array}{l}\text { Seringnya kelolosan } \\
\text { inspeksi ban pada } \\
\text { tiap tiap proses } \\
\text { produksinya }\end{array}$ & $\begin{array}{l}\text { Sebaiknya dilakukan } \\
\text { pemberian training } \\
\text { pada karyawan }\end{array}$ \\
\hline $\begin{array}{l}\text { Kurang } \\
\text { pengecek } \\
\text { an ban }\end{array}$ & $\begin{array}{l}\text { Pada saat memasukan } \\
\text { ban ke dalam proses } \\
\text { produksi karyawan } \\
\text { kurang teliti memilih } \\
\text { ban yang layak atau } \\
\text { tidak layak untuk di } \\
\text { masukkan pada saat } \\
\text { proses produksi }\end{array}$ & $\begin{array}{lr}\text { Sebaiknya } & \text { dilakukan } \\
\text { pengawasan } & \text { oleh } \\
\text { kepala } & \text { produksi } \\
\text { secara rutin } & \end{array}$ \\
\hline
\end{tabular}

Tabel 2. Rekomendasi (lanjutan)

\begin{tabular}{|c|c|c|}
\hline Problem & Dampak & Rekomendasi \\
\hline $\begin{array}{l}\text { Pengecekan } \\
\text { envelope }\end{array}$ & $\begin{array}{l}\text { Pengisian ban } \\
\text { kurang } \\
\text { maksimal }\end{array}$ & $\begin{array}{l}\text { Dilakukan } \\
\text { pengecekan mesin } \\
\text { tiap hari guna } \\
\text { mengurangi } \\
\text { kecacatan pada } \\
\text { proses produksi. }\end{array}$ \\
\hline $\begin{array}{l}\text { SOP tidak } \\
\text { diterapkan }\end{array}$ & $\begin{array}{l}\text { pada proses } \\
\text { produksinya } \\
\text { pekerja } \\
\text { mengabaikan } \\
\text { SOP mereka } \\
\text { hanya } \\
\text { menggunakan } \\
\text { perkiraan } \\
\text { mereka } \\
\text { sehingga tiap } \\
\text { bagian yang } \\
\text { pada proses } \\
\text { produksi tidak } \\
\text { terstandarisasi }\end{array}$ & $\begin{array}{l}\text { Dilakukan brefing } \\
\text { tiap minggu untuk } \\
\text { mengarahkan } \\
\text { pekerja agar bekerja } \\
\text { secara SOP } \\
\text { sehingga proses } \\
\text { produksinya sesuai } \\
\text { dengan standart. }\end{array}$ \\
\hline $\begin{array}{l}\text { Minimnya } \\
\text { container } \\
\text { pendingin }\end{array}$ & $\begin{array}{l}\text { Produk tidak } \\
\text { ditempatkan } \\
\text { di tempat } \\
\text { yang tepat }\end{array}$ & $\begin{array}{l}\text { Membeli container } \\
\text { pendingin. }\end{array}$ \\
\hline $\begin{array}{l}\text { Kurangnya } \\
\text { pengecekan } \\
\text { chamber }\end{array}$ & $\begin{array}{l}\text { Terjadi } \\
\text { kecacatan } \\
\text { produk dalam } \\
\text { proses }\end{array}$ & $\begin{array}{l}\text { Perawatan mesin } \\
\text { curing secara } \\
\text { berkala }\end{array}$ \\
\hline $\begin{array}{l}\text { Bahan baku } \\
\text { tidak sesuai } \\
\text { standar }\end{array}$ & $\begin{array}{l}\text { Bahan baku } \\
\text { yang diterima } \\
\text { kurang baik } \\
\text { dan tetap di } \\
\text { produksi } \\
\text { sehingga } \\
\text { bahan baku } \\
\text { memiliki } \\
\text { kualitas yang } \\
\text { kurang. }\end{array}$ & $\begin{array}{l}\text { Memilih supliyer } \\
\text { yang baik untuk } \\
\text { mendapatkan bahan } \\
\text { baku yang baik }\end{array}$ \\
\hline $\begin{array}{l}\text { Cairan } \\
\text { cusion gum }\end{array}$ & $\begin{array}{l}\text { Ban tidak } \\
\text { dapat } \\
\text { menempel } \\
\text { pada tread }\end{array}$ & $\begin{array}{l}\text { Melakukan proses } \\
\text { penempelan dengan } \\
\text { memberikan standar } \\
\text { untuk cairan cusion } \\
\text { gum. }\end{array}$ \\
\hline $\begin{array}{l}\text { Suhu } \\
\text { ruangan } \\
\text { panas }\end{array}$ & $\begin{array}{l}\text { Pekerja } \\
\text { merasa kurang } \\
\text { nyaman pada } \\
\text { proses } \\
\text { produksinya. } \\
\text { pekerja } \\
\text { merasa bising } \\
\text { sehingga } \\
\text { kurang fokus } \\
\text { pada } \\
\text { pekerjaannya. }\end{array}$ & $\begin{array}{l}\text { Ventilasi udara } \\
\text { diperbaiki lagi } \\
\text { untuk mendapatkan } \\
\text { suhu yang nyaman } \\
\text { di dalam ruangan } \\
\text { Pekerja harus } \\
\text { dikasih alat } \\
\text { pelindung } \\
\text { keselamatan kerja } \\
\text { seperti air plug } \\
\text { untuk meredam } \\
\text { kebisingan }\end{array}$ \\
\hline $\begin{array}{l}\text { Ruangan } \\
\text { kotor }\end{array}$ & $\begin{array}{l}\text { pekerja } \\
\text { kurang } \\
\text { nyaman dan } \\
\text { mengakibatka } \\
\text { n pekerja } \\
\text { tidak fokus. }\end{array}$ & Penerapan $5 \mathrm{R}$ \\
\hline
\end{tabular}




\section{SIMPULAN}

Berdasarkan penelitian yang dilakukan, ditemukan bahwa faktor yang menyebabkan defect ban 1000 ring 20 terdiri dari lima, yaitu faktor pekerja, mesin, bahan baku, lingkungan kerja dan metode pelaksaan pekerjaan. Berdasarkan faktor-faktor tersebut, terdeteksi tiga belas potensi kejadian akar penyebab permasalahan. Tiga penyebab permasalahan dikarenakan factor human error yaitu karyawan kurang maksimal pada proses inspeksi diketahui bahwa pada proses produksi pada bagian insial inspeksion operatornya sering kelolosan dan menyebkan terhambatnya waktu produksi. Akar penyebab permasalahan kedua yaitu kurangnya pengecekan ban, terutama pada pada saat memasukan ban ke dalam proses produksi karyawan kurang teliti memilih ban yang layak atau tidak layak untuk di masukkan pada saat proses produksi. Ketiga yaitu kurangnya pengecekan envelope, pada proses ini karyawan kurang mengetahui standart pasti pengisian angin ban untuk dimasukkan ke curring.

Mesin sebagai alat bantu proses vulkanisir teridentifikasi menjadi penyebab defect kembung dan defect tidak matang. Tiga akar permasalahan penyebab tidak matang tersebut yaitu mesin rimming kurang maksimal, pada proses rimming sering kali mengalami kendala pada saat pemasangan pelek ban. Kedua yaitu mesin curing kurang stabil, terjadi pada proses pemanasan ban suhu yang kurang stabil bisa menyebabkan vulkanisir ban mengalami banyak kecacatan seperti kembung dan tidak matang. Ketiga yaitu mesin filling kurang panas, terjadi pada saat penambalan ban, pada mesin tersebut kurang optimal untuk digunakan. Tiga akar penyebab defect kembung yaitu suhu curing tidak stabil, ada proses pemanasan ban sehingga suhu yang kurang stabil bisa menyebabkan vulkanisir ban mengalami banyak kecacatan kembung. Mesin skiving kurang maksimal, menyebabkan proses pelubangan ban hasil proses buffing tidak sesuai standart yang ditetapkan dan tekanan udara ban kurang maksimal dikarenakan kurang stabilnya mesin envelople

Terdeteksi tiga akar permasalahan yang disebabkan factor metode kerja. Pertama yaitu pelaksaan proses vulkanisir SOP tidak diterapkan, pada proses produksinya pekerja mengabaikan sop mereka hanya menggunakan perkiraan mereka sehingga tiap bagian yang pada proses produksi tidak terstandarisasi. Kedua yaitu minimnya container pendingin dikarenakan kapasitas pendingin yang kurang dengan hasil produksi yang di capai perusahaan. Penyebab permasalahan terjadinya defect ketiga yaitu kurangnya pengecekan chamber atau curing, pada proses ini suhu curing kurang diperhatikan sehingga sering terjadi kecacatan pada proses tersebut.

Dua akar permasalahan penyebab defect disebabkan factor bahan baku yaitu bahan baku memiliki mutu dibawah standar, bahan baku yang diterima kurang baik dan tetap di produksi sehingga bahan baku tersebut memiliki kualitas yang kurang baik dan rentang cacat. Selanjutnya bahan cairan cusion gum kurang menempel di ban sehingga ban tersebut tidak bisa menempel dengan tread.

Suhu ruangan di lokasi proses vulkanisir yang tidak memiliki ventilasi udara yang baik sehingga mengakibatkan suhu ruangan panas, tingkat kebisingan di ruang kerja, dan kebrsihan di area pelaksanaan kerja kurang terjaga merupakan tiga akar penyebab permasalahan disebabkan oleh faktor lingkungan kerja.

Berdasarkan hasil analisis mengenai proporsi defect dalam produk ban 1000 ring 20, maka dapat disimpulkan bahwa produk tersebut masih dalam batas kendali. Namun berdasarkan standart toleransi perusahaan, persentase defect yang ada masih berada di luar standart yang telah di tetapkan yaitu 1 persen. 
Rekomendasi berdasarkan brainstorming dengan team manajemen mutu yang dapat berikan agar dapat mengurangi produk defect adalah perawatan mesin curing dan mesin skiving secara preventif. Selanjutnya direkomendasikan pemberian motivasi kepada karyawan berupa training motivasi dan pengawasan oleh kepala produksi secara rutin. Selanjutnya dilakukan briefing tiap minggu untuk mengarahkan pekerja agar bekerja secara SOP sehingga proses produksinya sesuai dengan standart yang telah ditetapkan. Pemilihan supliers dilakukan ulang serta menetapkan kriteria pemilihan pemasok secara ketat agar didapat bahan baku sesuai standar perusahaan. Rekomendasi selanjutnya adalah ventilasi udara diperbaiki lagi untuk mendapatkan suhu yang nyaman di dalam ruangan dan pekerja dilengkapi dengan alat pelindung keselamatan kerja seperti air plug untuk meredam kebisingan dan Penerapan 5 R.

\section{DAFTAR PUSTAKA}

[1] D. Ariani, Manajemen Operasi Jasa, Yogyakarta: Graha Ilmu, 2009.

[2] E. Yusnita dan R. Puspita, "Analisa pengendalian kualitas paving block dengan metode new seven tools di CV. Arga Reyhan Bahari Sumatera Utara," JIME, vol. 4, no. 2, pp.1 -11, 2020.

[3] Suparjo dan E. F, "Analisis pengendalian kualitas produk polyurethane sandwich panel dengan metode old seven tools di PT. ABC," Jurnal Hasil Penelitian, vol. 4, no. 2, pp. 114-119, 2019.

[4] M. Akbar, Agustian dan Sunardi, "Analisis kualitas kapur menggunakan metode quality control circle dan seven tools di PT. Timbul Persada," Jurnal Juminten, vol. 1, no. 5, pp. 121-132, 2020.

[5] V. Gaspersz, Total Quality Management, Jakarta: Gramedia,
2003.

[6] Ratnadi dan E. Saputro, "Pengendalian kualitas produksi menggunakan alat bantu statistik (seven tools) dalam upaya menekan tingkat kerusakan produk," Jurnal Indept, vol. 6, no. 2, pp. -, 2016.

[7] E. Haryanto dan I. Novalis, "Analisis pengendalian kualitas produk bor rotor pada proses mesin cnc lathe dengan metode seven tools," Jurnal Teknik, vol. 8, no. 1, pp. 69-77, 2019.

[8] M. R. Rosyidi dan Hermanto, "Analisis kualitas ikan bandeng dengan metode seven tools ditempat pelelangan ikan (TPI) Lumpur Gresik," Kaizen: MS\&IEJ, vol. 1, no. 2, pp. 23-31, 2018.

[9] T. P. Matondong dan U. M. M, "Aplikasi seven tools untuk mengurangi cacat produk white body pada mesin roller," Jurnal Sistem dan Manajemen Industri, ol. 2, no. 2, pp. 59-66, 2018.

[10] M. Ulkhaq, S. N.W.P dan R. Hakim, "Aplikasi seven tools untuk mengurangi cacat produk pada mesin communite di PT. Massacom Graphy Semarang," Jurnal Pasti, vol. 11, no. 2, pp. 220-230, 2017.

[11] W. D. Putro, Suryadi dan C. R, "Pengendalian kualitas produksi rear caliper breake system type 2 pv untuk sepeda motor menggunakan metode seven tools," Jurnal Rekayasa Mesin, vol. 12, no. 1, pp. -, 2017.

[12] Soflyanurriyanti dan H. M, "Pengendalian kualitas proses produksi kayu olahan turning dengan menggunakan metode seven tools di CV. Gavra Perkasa," Jurnal Bina Teknika, vol. 14, no. 2, pp. 217-223, 2018.

[13] Somadi, S. Benowo dan P. PO, "Evaluasi kerusakan barang dalam proses pengiriman dengan 
menggunakan metode seven tools," Jurnal Intech, vol. 6, no. 1, pp. 1-11, 2020.

[14] R. A. Asmoro dan M. M, "Analisa produk reject pada produk $600 \mathrm{ML}$ dengan metode seven tools di PT. Tirta Investama Pandaan," Journal Knowledge Industrial Engineering, Vol.1. Pp 2460-01131, 2016.
[15] Irwan dan D. Haryono, Pengendalian Kualitas Statistik ( Pendekatan Teoritis dan Aplikatif ), Bandung: Alfabeta, 2015. 